\title{
Estimating the basal melt rate at NorthGRIP using a Monte Carlo technique
}

\author{
Susanne L. BUCHARDT, Dorthe DAHL-JENSEN \\ Ice and Climate, Niels Bohr Institute, University of Copenhagen, Juliane Maries vej 30, DK-2100 Copenhagen OE, Denmark \\ E-mail: lilja@gfy.ku.dk
}

\begin{abstract}
From radio-echo sounding (RES) surveys and ice core data it can be seen that the ice sheet is melting at the base in a large area in Northern Greenland. The RES images reveal internal layers in the ice. The layers are former deposition surfaces and are thus isochrones. Undulations of the isochrones in regions where the base is smooth suggest that the basal melt rate changes over short distances. This indicates that the geothermal heat flux is very high and has large spatial variability in Northern Greenland. In this study, the basal melt rate at the NorthGRIP drill site in North-Central Greenland is calculated by inverse modelling. We use simple one- and two-dimensional flow models to simulate the ice flow along the NNW-trending ice ridge leading to NorthGRIP. The accumulation is calculated from a dynamical model. Several ice flow parameters are unknown and must be estimated along with the basal melt rate using a Monte Carlo method. The Monte Carlo inversion is constrained by the observed isochrones, dated from the timescale established for the NorthGRIP ice core. The estimates of the basal melt rates around NorthGRIP are obtained from both the one- and two-dimensional models. Combining the estimated basal melt rates with the observed borehole temperatures allows us to convert the basal melt rates to geothermal heat flow values. From the two-dimensional model we find the basal melt rate and geothermal heat flux at NorthGRIP to be $6.1 \mathrm{~mm} \mathrm{a}^{-1}$ and $129 \mathrm{~mW} \mathrm{~m}^{-2}$, respectively.
\end{abstract}

\section{INTRODUCTION}

The NorthGRIP (North Greenland Ice Core Project) ice core was drilled during $1996-2004$ at $75.10^{\circ} \mathrm{N}, 42.32^{\circ} \mathrm{W}$, $316 \mathrm{~km}$ NNW of the GRIP drill site in Central Greenland. The ice in the area flows along a NNW-trending ice ridge from GRIP towards NorthGRIP. The surface velocity at NorthGRIP is $1.3 \mathrm{~m} \mathrm{a}^{-1}$ (Hvidberg and others, 2002), the ice thickness is $3090 \mathrm{~m}$ and the present mean annual temperature is $-31.5^{\circ} \mathrm{C}$. The aim of the drilling was to retrieve ice from the Eemian interglacial period 130-115 kyr ago. Before drilling was initiated, it was predicted that the Eemian layer would be found at depths of 2750-2850 m (Dahl-Jensen and others, 1997). However, as bedrock was approached it became evident that the ice was melting at the bottom. The basal layers did not thin as fast as was expected, and Eemian ice was not encountered until $80 \mathrm{~m}$ above bedrock (North Greenland Ice Core Project members, 2004). When it had been established that there is basal melting at NorthGRIP, it was concluded from radio-echo sounding (RES) images that the ice must be melting at the base in a large area in Northern Greenland. As the geothermal heat flux in the area is unknown, it is not straightforward to calculate the melt rate at NorthGRIP. Furthermore, the shape of the RES layers suggests that the melt rate varies significantly over short distances in the area (Dahl-Jensen and others, 2003). Using a Monte Carlo method to invert an ice flow model for the flow line from GRIP to NorthGRIP allows us to estimate the melt rates in the area around NorthGRIP.

\section{MODELLING THE ICEFLOW}

A Dansgaard-Johnsen model (Dansgaard and Johnsen, 1969) is used to simulate the ice flow along the flowline from GRIP to NorthGRIP. Both one- and two-dimensional approaches are used. For this purpose, a coordinate system is adopted with a horizontal $x$ axis along the NNW-trending ice ridge in the direction of the flow at NorthGRIP, and a vertical $z$ axis pointing upwards. The origin of this coordinate system is located at GRIP at sea level. This study has been concerned with a $104 \mathrm{~km}$ long section of the ridge starting $82 \mathrm{~km}$ upstream from NorthGRIP and ending $22 \mathrm{~km}$ downstream. Accounting for melting and sliding at the base, and assuming constant ice thickness with time, the horizontal velocity $u$ and the vertical velocity $w$ are given by

$$
u= \begin{cases}u_{\text {sur }} & z \in[h, H] \\ u_{\text {sur }}\left(F_{\mathrm{B}}+\left(1-F_{\mathrm{B}}\right) \frac{z}{h}\right) & z \in[0, h],\end{cases}
$$

and

$$
w= \begin{cases}w_{0}+\frac{\partial w_{\text {sur }}}{\partial z}\left(z-\frac{1}{2} h\left(1-F_{\mathrm{B}}\right)\right) & z \in[h, H] \\ w_{0}+\frac{\partial w_{\text {sur }}}{\partial z}\left(F_{\mathrm{B}} z+\frac{1}{2}\left(1-F_{\mathrm{B}}\right) \frac{z^{2}}{h}\right) & z \in[0, h],\end{cases}
$$

respectively. Here $u_{\text {sur }}$ is the horizontal surface velocity, $z$ the ice equivalent height above bedrock, $F_{\mathrm{B}}=u_{\text {bed }} / u_{\text {sur }}$ the fraction of basal sliding, $H$ the ice thickness in ice equivalent and $h$ is called the kink height. The vertical velocity at the base is $w_{0}$, and

$$
\frac{\partial w_{\text {sur }}}{\partial z}=-\frac{a+w_{0}}{H-\frac{1}{2} h\left(1-F_{\mathrm{B}}\right)}
$$

where $a$ is the annual ice equivalent accumulation. The basal melt rate $w_{\mathrm{b}}$ is given by $w_{\mathrm{b}}=-w_{0}$. The onedimensional model is obtained by disregarding the horizontal movement, $u=0$.

In the two-dimensional model, the basal melt rate is allowed to vary along the flowline, changing value every $4 \mathrm{~km}$. The melt rate is considered constant within each of these $4 \mathrm{~km}$ intervals. In order to limit the number of parameters to be determined by the Monte Carlo inversion, the kink height $h$ and the fraction of basal sliding $F_{\mathrm{B}}$ are 

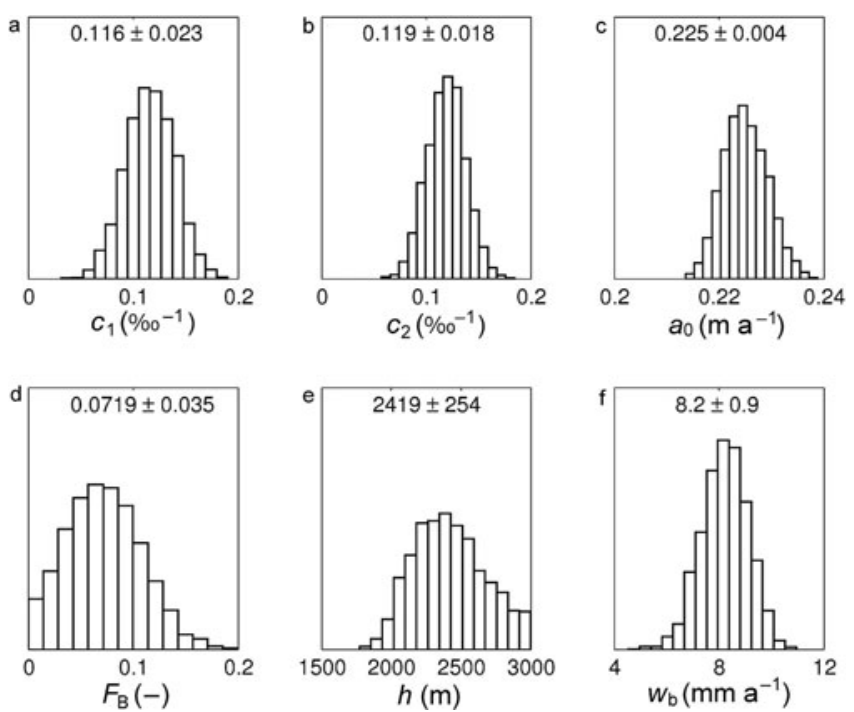

Fig. 1. Histograms of accepted values for parameters of the onedimensional model; mean and standard deviation are displayed above each distribution. (a), (b) The relative slopes of the accumulation rate in warm $\left(c_{1}\right)$ and cold $\left(c_{2}\right)$ climate, respectively (Equation (8)). (c) The present ice equivalent accumulation rate at NorthGRIP $a_{0}$. (d) The fraction of basal sliding, $F_{B}$. (e) The kink height $h$ from the Dansgaard-Johnsen model (Equations (1) and (2)). (f) The basal melt rate at NorthGRIP, $w_{\mathrm{b}}$.

considered linear functions of the melt rate:

$$
\begin{aligned}
h & =\alpha w_{\mathrm{b}}+h_{0} \\
F_{\mathrm{B}} & =\beta w_{\mathrm{b}} .
\end{aligned}
$$

Thus $h$ and $F_{\mathrm{B}}$ also vary from one $4 \mathrm{~km}$ interval to another. Dahl-Jensen and others (1997) obtained estimates for the present accumulation rates along the flow line from shallow ice core studies. In the present work, it is assumed that the ratio of the accumulation rate at any point along the line to that at NorthGRIP is constant in time. Thus, the accumulation history at any point along the line can be inferred from the accumulation history at NorthGRIP $a(t)$ which is calculated from the accumulation model presented below.

The ice thickness at NorthGRIP is assumed to be constant in time in agreement with model results (Letréguilley and others, 1991; Marshall and Cuffey, 2000). All the parameters of the flow model except the accumulation rate $a$ are thus assumed to be constant in time. $\alpha, \beta, h_{0}$ and the value of $w_{\mathrm{b}}$ within each $4 \mathrm{~km}$ interval are unknown and will be estimated using a Monte Carlo inversion of the flow model.

\section{THE ACCUMULATION MODEL}

The accumulation history at the NorthGRIP drill site is calculated using a model of the same type as that used by Johnsen and others (1995) to date the GRIP ice core. The time-dependent ice equivalent accumulation rate $a(t)$ is calculated from the measured $\delta^{18} \mathrm{O}$ values:

$$
\begin{gathered}
a(t)=a_{0} \exp (R) \\
R=k_{2}\left(\delta^{18} \mathrm{O}(t)-\delta^{18} \mathrm{O}_{\mathrm{w}}\right)+\frac{1}{2} k_{1}\left(\delta^{18} \mathrm{O}(t)^{2}-\delta^{18} \mathrm{O}_{\mathrm{w}}^{2}\right) \\
k_{1}=\frac{c_{1}-c_{2}}{\delta^{18} \mathrm{O}_{\mathrm{w}}-\delta^{18} \mathrm{O}_{\mathrm{c}}} ; \quad k_{2}=c_{1}-\delta^{18} \mathrm{O}_{\mathrm{w}} k_{1}
\end{gathered}
$$

where $a_{0}$ is the present ice equivalent accumulation rate at
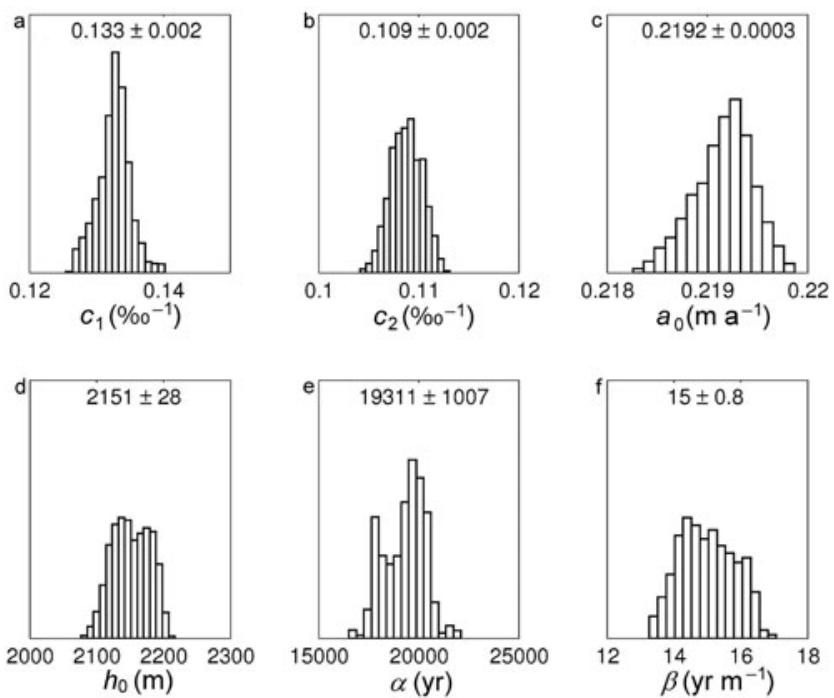

Fig. 2. Histograms of accepted values for parameters of the twodimensional model (see Fig. 3 for the melt rates); mean and standard deviation are displayed above each distribution. (a), (b) The relative slopes of the accumulation rate in warm $\left(c_{1}\right)$ and cold $\left(c_{2}\right)$ climate, respectively. (c) The present ice equivalent accumulation rate at NorthGRIP $a_{0}$. (d), (e) The parameters $h_{0}$ and $\alpha$ linking the kink height to the melt rate (Equation (4)). (f) The link $\beta$ between the fraction of bottom sliding and the basal melt rate (Equation (5)).

NorthGRIP and $\delta^{18} \mathrm{O}_{w}=-35.2 \%$ and $\delta^{18} \mathrm{O}_{\mathrm{c}}=-42 \%$ are typical $\delta^{18} \mathrm{O}$ values for warm and cold climate at NorthGRIP, respectively. $c_{1}$ and $c_{2}$ denote the relative slopes of $a$ in warm and cold climate, respectively, and are defined as

$$
c_{1}=\left.\frac{1}{a} \frac{\partial a}{\partial \delta^{18} \mathrm{O}}\right|_{\delta^{18} \mathrm{O}_{\mathrm{w}}} ; \quad c_{2}=\left.\frac{1}{\mathrm{a}} \frac{\partial \mathrm{a}}{\partial \delta^{18} \mathrm{O}}\right|_{\delta^{18} \mathrm{O}_{\mathrm{c}}} .
$$

The parameters $a_{0}, c_{1}$ and $c_{2}$ are found from the Monte Carlo inversion. The GICC05 timescale (Rasmussen and others, 2005; Vinther and others, 2006) is used for the $\delta^{18} \mathrm{O}$ curve back to $42 \mathrm{kyr}$ b2k (before $2000 \mathrm{AD}$ ), and further back in time the ss09sea timescale (Johnsen and others, 2001) is used. However, the ss09sea timescale has been shifted to agree with the GICC05 at $42 \mathrm{kyr}$ b2k. The measured $\delta^{18} \mathrm{O}$ values have been corrected for the changes in the isotopic composition of seawater due to the build up of ice on the continents during the glacial period (Waelbroeck and others, 2002).

\section{MONTE CARLO INVERSION}

In the one-dimensional model, the horizontal velocity is $u=0$ and only the basal melt rate at NorthGRIP is included. Thus the kink height $h$ and the fraction of basal sliding $F_{\mathrm{B}}$ are included directly as model parameters instead of $\alpha, h_{0}$ and $\beta$ (see Equations (4) and (5)). This reduces the number of model parameters to be determined by the Monte Carlo inversion to 6: $c_{1}, c_{2}, a_{0}, F_{\mathrm{B}}, h$ and $w_{\mathrm{b}}$.

In the two-dimensional model, the basal melt rate $w_{\mathrm{b}}$ has 26 unknown values, one for each $4 \mathrm{~km}$ along the $104 \mathrm{~km}$ long flowline. Together with $\alpha, h_{0}$ and $\beta$ from Equations (4) and (5) and $c_{1}, c_{2}$ and $a_{0}$ of the accumulation model it adds up to a total of 32 unknown model parameters.

An observed data set exists $\boldsymbol{d}^{\text {obs }}$ consisting of 20 internal layers identified in the RES images (Chuah and others, 1996; Dahl-Jensen and others, 1997; Gogineni and others, 1998, 

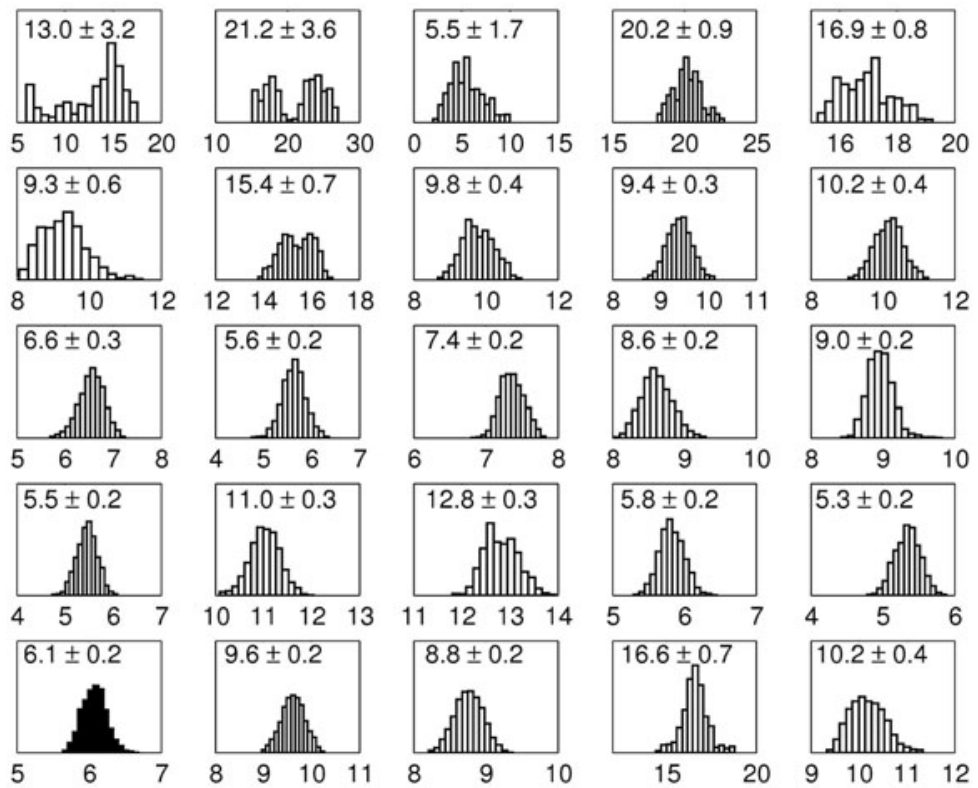

Fig. 3. Histograms of accepted values of the basal melt rate at $4 \mathrm{~km}$ intervals along the flow line. The measurements closest to GRIP are displayed at the top left, and those furthest from GRIP are at the lower right. The histogram for the interval containing NorthGRIP is shown in black. The units are $\mathrm{mm} \mathrm{a}^{-1}$.

2001; Fahnestock and others, 2001; Kanagaratnam and others, 2001). The layers are generally accepted to be isochrones. They have been dated from their depths $(600-$ $2700 \mathrm{~m}$ ) in the NorthGRIP ice core using the same timescale as for the $\delta^{18} \mathrm{O}$ record. This gives isochrone ages from 3.579.6 kyr. We will now use the ice flow model and the observed data to calculate the unknown model parameters as an inverse problem. Since the problem is highly nonlinear we turn to a Monte Carlo method in order to solve it. The model space is investigated through a random walk. For each step in the random walk, a modelled data set $\boldsymbol{d}(\boldsymbol{m})$ is created by running the forward flow model with the combination $\boldsymbol{m}$ of unknown model parameters. This is compared to the observed data set by calculating the misfit function $S$ :

$$
S(\boldsymbol{m})=\frac{1}{2} \sum_{i} \sum_{j} \frac{\left(d_{i j}^{\mathrm{obs}}-d_{i j}\right)^{2}}{s_{i j}^{2}}
$$

where $i=1-20$ as there are 20 isochrones and $j$ runs through the 81 data points followed on each isochrone. $s_{i j}$ denotes the uncertainty in a data point $d_{i j}^{\text {obs }}$. This uncertainty is given by the vertical resolution of the radar used to measure data. The starting point of the forward model is $79.6 \mathrm{kyr}$ ago, since we do not have older isochrones to compare. The model is run to the present time in steps of 100 years. The likelihood function $L$ is given by

$$
L(\boldsymbol{m})=k \exp (-S(\boldsymbol{m}))
$$

where $k$ is a normalization constant. Each step of the random walk is accepted or rejected according to the Metropolis criterion

$$
P_{\text {accept }}=\min \left(1, \frac{L\left(\boldsymbol{m}_{\text {test }}\right)}{L\left(\boldsymbol{m}_{\text {current }}\right)}\right)
$$

where $\boldsymbol{m}_{\text {current }}$ is the most recently accepted model and $\boldsymbol{m}_{\text {test }}$ is the model being tested. It can be shown that this random walk samples the posterior probability density in the model space (Mosegaard and Tarantola, 1995). The final result is independent of the choice of initial values for the unknown model parameters.

\section{RESULTS}

\section{One-dimensional inversion}

The random walk in the model space was continued until a reasonable statistic was obtained. In the results presented here, 300000 models were accepted. The distributions of the accepted values for each model parameter are shown in Figure 1. The mean and standard deviation for each distribution are displayed above the histograms. All distributions are seen to resemble Gaussian distributions, with strong single maxima. This means that the parameters are well defined by the Monte Carlo inversion.

The result for the melt rate at NorthGRIP is found to be $8.2 \pm 0.9 \mathrm{~mm} \mathrm{a}^{-1}$. When the melt rate is known, the amount of heat used to melt the ice $Q_{\text {melt }}$ can be calculated using the relation

$$
Q_{\text {melt }}=\rho w_{\mathrm{b}} L_{\text {ice }}
$$

where $\rho$ and $L_{\text {ice }}$ are the density and latent heat of ice, respectively. The geothermal heat flux $Q_{\text {geo }}$ is given by the sum of the amount of heat used to melt the ice and the amount of heat conducted through the ice $Q_{\text {ice }}$ :

$$
Q_{\text {geo }}=Q_{\text {melt }}+Q_{\text {ice }} \text {. }
$$

$Q_{\text {ice }}$ is determined from the gradient of the observed temperature profile $\partial T / \partial z$ at the base at NorthGRIP, i.e.

$$
Q_{\text {ice }}=-K \frac{\partial T}{\partial z}
$$

where $K$ is the thermal conductivity of ice. Using $Q_{\text {ice }}=70 \mathrm{~mW} \mathrm{~m}^{-2}$ (North Greenland Ice Core Project members, 2004) and the basal melt rate found in this study, the geothermal heat flux at NorthGRIP is calculated to be $150 \pm 12 \mathrm{~mW} \mathrm{~m}^{-2}$. 

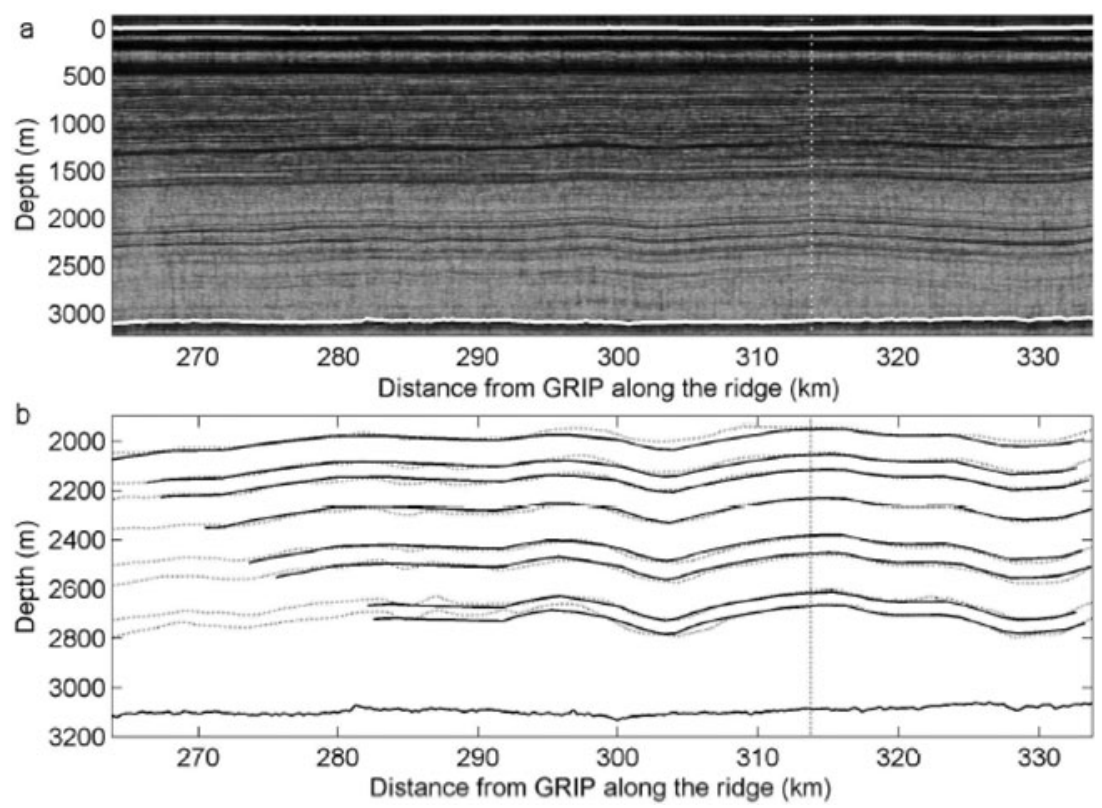

Fig. 4. (a) RES image collected along the ice ridge between GRIP and NorthGRIP. The surface and bedrock are shown in white. NorthGRIP is indicated by the vertical dotted line. (b) Comparison between observed (dotted) and modelled (solid) isochrones in the lower part of the ice sheet. The shown isochrones have been dated to 28.6, 34.6, 37.6, 44.7, 53.8, 59.7, 75.2 and $79.6 \mathrm{kyr}$ b2k, respectively. The bedrock is shown in the bottom of the plot. The modelled isochrones are seen to reproduce the large-scale undulations of the observed isochrones. Higher accumulation rate and higher melt rate cause the isochrones to be located deeper in the ice sheet upstream (left) from the drill site.

\section{Two-dimensional inversion}

In this inversion, the full suite of 32 model parameters was determined. The random walk in the model space was continued until a reasonable statistic was obtained. In the results presented here, 250000 models were accepted. The distributions of the accepted values for the model parameters are shown in Figures 2 and 3. The three parameters from the accumulation model $\left(c_{1}, c_{2}\right.$ and $\left.a_{0}\right)$ are all well determined by the Monte Carlo inversion (Figs $2 \mathrm{a}-\mathrm{C}$ ), while the distributions for $\alpha$ and $h_{0}$ both show a double peak. The consequence is that the kink height $h$ calculated from Equation (4) is not well determined by the inversion. However, the peaks are close together so the effect on the determination of the basal melt rates is small.

The basal melt rates are well determined for all the $4 \mathrm{~km}$ long intervals except the first five (see Fig. 3). The effect of basal melting on the internal layers increases with depth, so the deep layers are very important for the determination of the melt rates. Due to the horizontal movement of the ice, the modelled isochrones have moved out of the first intervals before they have reached great depths. As a consequence, the inversion has not had any constraints in the deep part of the ice for the first part of the line, and the melt rate estimates obtained for that area are badly constrained. The melt rate is seen to vary between $5.3 \pm 0.2 \mathrm{~mm} \mathrm{a}^{-1}$ and $21.2 \pm 3.6 \mathrm{~mm} \mathrm{a}^{-1}$ with the smallest value just upstream from the NorthGRIP drill site. The melt rate at NorthGRIP is found to be $6.1 \pm 0.2 \mathrm{mma}^{-1}$. This is considerably lower than the estimate obtained from the one-dimensional model. The higher melt rates upstream from the drill site pull the internal layers down before the ice reaches the NorthGRIP drill site. The one-dimensional model thus compensates for the upstream effect by over-estimating the melt rate.

Figure 4 shows a comparison between observed and modelled isochrones in the lower part of the ice sheet. It can be seen that the modelled isochrones successfully reproduce the large-scale variations of the observed isochrones.

Figure 5 shows a comparison between the shape of the lowest observed isochrone dated to $79.6 \mathrm{kyr}$ b2k and the variation of the melt rate along the line. The two curves show very similar patterns, but the isochrone curve is shifted slightly to the right. The shift is caused by the horizontal flow velocity of the ice. The features created by the melt rate at a given place is carried with the ice along the line. This illustrates the advantage of using a two-dimensional model to simulate the ice flow.

Using Equations (12) and (13) and $Q_{\text {ice }}=70 \mathrm{~mW} \mathrm{~m}^{-2}$, the geothermal heat flux at NorthGRIP is determined to be $129 \pm 2 \mathrm{~mW} \mathrm{~m}^{-2}$. Both upstream and downstream from the drill site, significantly higher values of the geothermal heat flux are found.

\section{DISCUSSION}

The above stated uncertainties are the standard deviations of the histograms of accepted model values. They only reflect the precision with which the Monte Carlo inversion is able to determine the value of the parameters and do not include uncertainties arising from model deficiencies and assumptions. The total uncertainties of the parameters are therefore believed to be larger than the stated standard deviations.

The ratio between the accumulation rate at NorthGRIP and at other locations along the flow line was assumed constant in time. At present the ratio of the accumulation at NorthGRIP to that at GRIP is $83 \%$, but Grinsted and DahlJensen (2002) found that this ratio was as low as $66 \%$ during the glacial period. This indicates that the accumulation ratio at other places along the line may also have changed in time. Consequently, the assumption of unchanged accumulation pattern along the line with time may be poor. The 

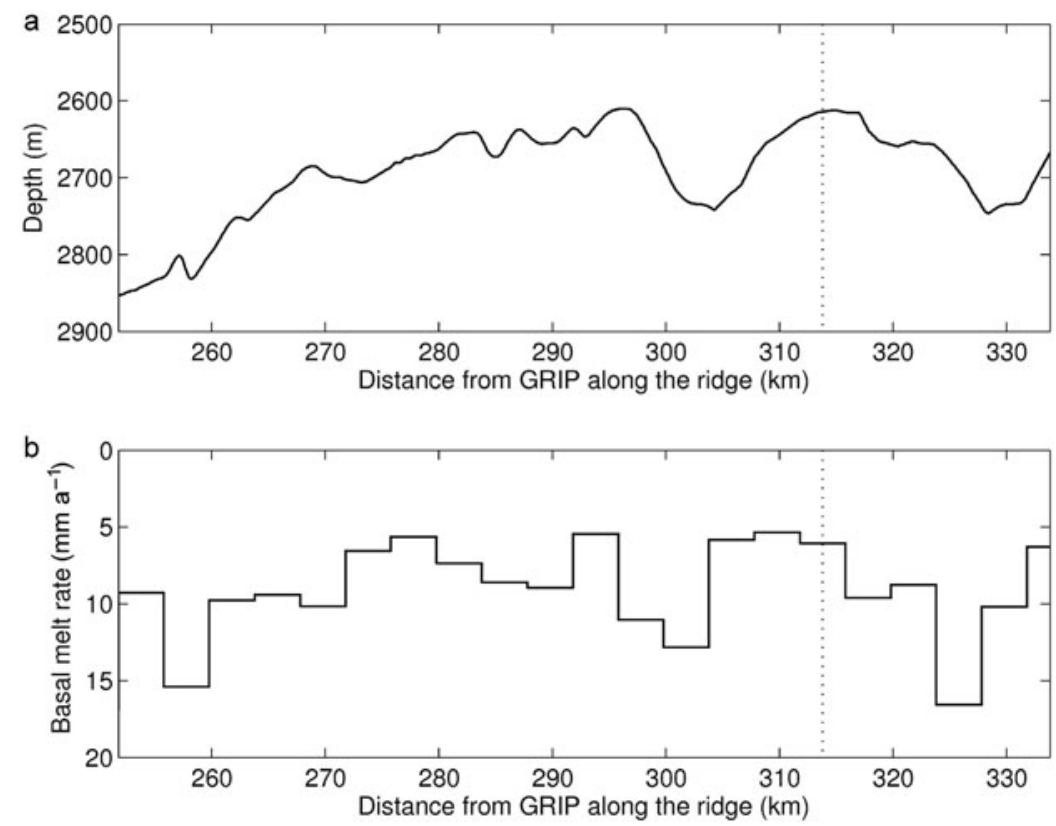

Fig. 5. (a) The lowest isochrone from the radar data set used in this study. (b) The melt rates along the line found from the Monte Carlo inversion. Notice the reversed melt rate axis. NorthGRIP is indicated by the dotted line.

results from Grinsted and Dahl-Jensen (2002) indicate that the accumulation pattern seen today in the area between GRIP and NorthGRIP was more pronounced during the glacial period. If this is the case, the accumulation rates used upstream from NorthGRIP in this model are slightly overestimated for the glacial period, resulting in an underestimation of the melt rates.

The fraction of basal sliding was assumed to be linearly related to the melt rate (Equation (5)). This is based on the premise that a higher melt rate will provide a larger amount of water to lubricate the bed and thus result in a larger sliding velocity. However, this assumption may not hold if the meltwater is drained from the area where it is produced e.g. through valleys or channels. Thus, in assuming Equation (5) is correct, we also assume that the meltwater does not move far from where it is produced.

This study aims to estimate the basal melt rate at NorthGRIP, yet we use a non-thermal model. This can be done because the basal melt rate equals minus the vertical velocity at the base of the ice sheet and thus can be treated as a flow law parameter. However, the melt rate depends on the temperature gradient at the base, which changes with time because the surface climate and therefore the temperature of the ice changes with time. Thus the melt rates found in this study may be considered as average values for the past $79.6 \mathrm{kyr}$.

Ice core studies have found values of $7 \mathrm{~mm} \mathrm{a}^{-1}$ and $140 \mathrm{~mW} \mathrm{~m}^{-2}$ for the basal melt rate and geothermal heat flux at NorthGRIP (North Greenland Ice Core Project members, 2004). These values fall in between the values found from the two- and one-dimensional models, and considering the assumptions made in the model, the results found in this study do not disagree with those obtained from ice core studies.

\section{CONCLUSIONS}

The basal melt rate at NorthGRIP is found to be $8.2 \mathrm{~mm} \mathrm{a}^{-1}$ using the one-dimensional model and $6.1 \mathrm{~mm} \mathrm{a}^{-1}$ using the two-dimensional model. The difference between the two numbers illustrates the importance of using a twodimensional model even though the computational time is significantly larger.

The basal melt rate is found to vary between $5.3 \mathrm{~mm} \mathrm{a}^{-1}$ and $21.2 \mathrm{~mm} \mathrm{a}^{-1}$ along the flowline. Assuming the variation is caused by geothermal heat flux variations, $Q_{\text {geo }}$ varies between $121 \mathrm{~mW} \mathrm{~m}^{-2}$ and $231 \mathrm{~mW} \mathrm{~m}^{-2}$ over scales of $10 \mathrm{~km}$. This requires the sources for the changes in geothermal heat flux to be located near the surface. Large spatial variations in the geothermal heat flux have also been reported by Näslund and others (2005). From studies of the Fennoscandian ice sheet during the Last Glacial Maximum they found significant local changes in the geothermal heat flux in Sweden and Finland. The values of the geothermal heat flux found in the present study are, however, quite high.

The drainage system of the meltwater created under the Greenland Ice Sheet is not well known. The water may be transported through small valleys observed in the bedrock topography. The presence of such canals may cause rapid spatial variations in the melt rate and is an alternative way of producing high local melt rates without strong changes in the geothermal heat flux. This is supported by the fact that dips in the isochrones are often observed over the small valleys in the bedrock.

\section{REFERENCES}

Chuah, T.S., S.P. Gogineni, C. Allen and B. Wohletz. 1996. Radar thickness measurements over the northern part of the Greenland ice sheet. Technical Report. 10470-3. Lawrence, KS, University of Kansas Center for Research Inc. Radar Systems and Remote Sensing Laboratory.

Dahl-Jensen, D. and 9 others. 1997. A search in north Greenland for a new ice-core drill site. J. Glaciol., 43(144), 300-306.

Dahl-Jensen, D., N. Gundestrup, S.P. Gogineni and H. Miller. 2003. Basal melt at NorthGRIP modeled from borehole, ice-core and radio-echo sounder observations. Ann. Glaciol., 37, 207-212. 
Dansgaard, W. and S.J. Johnsen. 1969. A flow model and a time scale for the ice core from Camp Century, Greenland. J. Glaciol., 8(53), 215-223.

Fahnestock, M., W. Abdalati, I. Joughin, J. Brozena and P. Gogineni. 2001. High geothermal heat flow, basal melt, and the origin of rapid ice flow in central Greenland. Science, 294(5550), 2338-2342.

Gogineni, S., T. Chuah, C. Allen, K. Jezek and R.K. Moore. 1998. An improved coherent radar depth sounder. J. Glaciol., 44(148), 659-669.

Gogineni, S. and 9 others. 2001. Coherent radar ice thickness measurements over the Greenland ice sheet. J. Geophys. Res., 106(D24), 33,761-33,772.

Grinsted, A. and D. Dahl-Jensen. 2002. A Monte Carlo-tuned model of the flow in the NorthGRIP area. Ann. Glaciol., 35, 527-530.

Hvidberg, C.S., K. Keller and N.S. Gundestrup. 2002. Mass balance and ice flow along the north-northwest ridge of the Greenland ice sheet at NorthGRIP. Ann. Glaciol., 35, 521-526.

Johnsen, S.J., D. Dahl-Jensen, W. Dansgaard and N.S. Gundestrup. 1995. Greenland paleotemperatures derived from GRIP borehole temperature and ice core isotope profiles. Tellus, 47B(5), 624-629.

Johnsen, S.J. and 8 others. 2001. Oxygen isotope and palaeotemperature records from six Greenland ice-core stations: Camp Century, Dye-3, GRIP, GISP2, Renland and NorthGRIP. J. Quat. Sci., 16(4), 299-307.

Kanagaratnam, P., S.P. Gogineni, N. Gundestrup and L. Larsen. 2001. High-resolution radar mapping of internal layers at the
North Greenland Ice Core Project. J. Geophys. Res., 106(D24), 33,799-33,811.

Letréguilly, A., N. Reeh and P. Huybrechts. 1991. The Greenland ice sheet through the last glacial-interglacial cycle. Palaeogeogr., Palaeoclimatol., Palaeoecol., 90(4), 385-394.

Marshall, S.J. and K.M. Cuffey. 2000. Peregrinations of the Greenland ice sheet divide in the last glacial cycle: implications for central Greenland ice cores. Earth Planet Sci. Lett., 179(1), 73-90.

Mosegaard, K. and A. Tarantola. 1995. Monte Carlo sampling of solutions to inverse problems. J. Geophys. Res., 100(B7), $12,431-12,447$.

North Greenland Ice Core Project members. 2004. High-resolution record of Northern Hemisphere climate extending into the last interglacial period. Nature, 431, 147-151.

Näslund, J.-O., P. Jansson, J.L. Fastook, J. Johnson and L. Andersson. 2005. Detailed spatially distributed geothermal heat-flow data for modeling of basal temperatures and meltwater production beneath the Fennoscandian ice sheet. Ann. Glaciol., 40, 95-101.

Rasmussen, S.O. and 15 others. 2006. A new Greenland ice core chronology for the last glacial termination. J. Geophys. Res. 111, D06102. (10.1029/2005JD006079.)

Vinther, B.M. and 12 others. 2006. A synchronized dating of three Greenland ice cores throughout the Holocene. J. Geophys. Res. 111, D13102. (10.1029/2005JD006921.)

Waelbroeck, C. and 7 others. 2002. Sea-level and deep water temperature changes derived from benthic foraminifera isotopic records. Quat. Sci. Rev., 21(1-3), 295-305. 